\title{
Incidence of G6PD Deficiency in a Tertiary Care Hospital in South India
}

\section{Chandrashekhar C ${ }^{1}$, Bandaru K ${ }^{2}$}

${ }^{1}$ Dr. Chandrashekar C, MBBS, MD, Associate Professor, ${ }^{2} \mathrm{Dr}$. Kasi Bandaru, MBBS, MD Resident. Both from the department of Paediatrics, JSS Medical College, JSS University, Mysore, India.

Address for correspondence:

Dr. Chandrashekar C

E-mail: chandruped23@gmail.com

Acknowledgements: None

Funding: $\mathrm{Nil}$

Conflict of Interest: None

Permission from IRB: Yes

Ethical dilemmas faced during study: No

\section{How to cite}

Chandrashekhar C, Bandaru K. Incidence of G6PD Deficiency in a Tertiary Care Hospital in South India. J Nepal Paediatr Soc 2016;36(2):141-142.

doi: http://dx.doi.org/10.3126/jnps.v36i2.14828

This work is licensed under a Creative Commons Attribution 3.0 License.

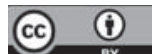

\begin{abstract}
Glucose-6-phosphate dehydrogenase (G6PD) deficiency is the commonest red cell enzymopathy affecting red cell metabolism. Its presentation can vary from drug induced haemolysis to neonatal jaundice with a prevalence ranging from $0-27 \%$ in India. The objective of this study was to find out the incidence of G6PD deficiency in babies delivered in our hospital and to assess its contribution in causing neonatal jaundice. 500 babies were screened for G6PD deficiency by Fluorescent spot test method. All the babies were found to have normal enzyme activity. Hence we concluded the burden of G6PD deficiency causing neonatal jaundice is less in our setup.
\end{abstract}

Key words: G6PD deficiency, screening programme, neonatal jaundice.

\section{Introduction}

G lucose-6-phosphate dehydrogenase (G6PD) deficiency is an $X$ linked inherited disorder commonly presenting as neonatal hyperbilirubinemia ${ }^{1}$. It is a cytoplasmic enzyme in the pentose monophosphate pathway and catalyses the conversion of nicotinamide adenine dinucleotide phosphate (NADP) to its reduced form, NADPH. It helps to protect the red blood cells (RBCs) from oxidative damage ${ }^{2}$. G6PD is commonly seen in African, South East Asian and middleeastern populations ${ }^{3,4}$. In India, the incidence of G6PD deficiency varies from 0 to $27 \%$. There are 13 biochemical variants of G6PD being reported so far out of which Mediterranean type is most common. Among the tribal, Orissa variant is frequently detected. The third common variant is Kerala Kalyan type ${ }^{5}$. G6PD deficiency is one of the important causes of severe neonatal hyperbilirubinemia, which can lead to kernicterus ${ }^{6}$. If detected early, children with this disorder can be reared with all the necessary precautions to lead a normal and healthy life. Hence, G6PD screening should be further reinforced for every newborn. The objective of this study was to find out the incidence of G6PD deficiency in babies delivered in our hospital and to assess its contribution in causing neonatal jaundice.

\section{Materials and Methods}

This prospective study was conducted in JSS Hospital from July 2012 to Jan 2013. 500 babies were screened for G6PD by Fluorescent 
Spot Test Method after the consent of parents and institutional ethical committee.Data regarding the antenatal history, consanguinity, geographical area of mother, birth order, mode of delivery, gestational age, birth injuries and blood group were documented. Cord blood was mixed with the reagent mixture in the ratio of $1: 10$ and a spot was made on a Whatman No.3 filter incubated at 65 room temperature and further spots made at 5,10,15, and 20 minutes respectively. The spots were allowed to dry and examined under a long wave UV lamp. In normal samples, the first spot showed fluoresce slightly, with increasing in fluorescence in the remaining spots indicating reduction of NADP to NADPH+H. G6PD deficient samples did not show fluorescence in any of the spots. Babies found to have G6PD deficiency were followed up for development of jaundice.

\section{Results}

All 500 babies screened for G6PD deficiency by fluorescent spot method, were found to have normal enzyme activity in our hospital. Out of 500 babies screened, 266(53.2\%) were males and 234 (46.3\%) were females. $469(93.3 \%)$ were term and $31(6.2 \%)$ are preterm. 43 babies out of 500 developed jaundice due to other causes.

\section{Discussion}

It is a known fact that the G6PD varies region to region. Since ours is a referral centre catering to Mysore city,India and surrounding areas, we aimed at looking for the G6PD deficiency in babies born in our hospital. We noted that there was no incidence of G6PD deficiency in this region. Our results were similar to a study done by Bhasin et al where regional distribution of G6PD deficiency showed $0 \%$ in Karnataka, $0.03 \%$ in Andhra Pradesh, and $0.07 \%$ in Tamilnadu 7 . In a similar study done in Delhi, the incidence of G6PD among 2479 neonates was $2 \%^{8}$. In Iran 2501 neonates were screened and the incidence was $3.2 \%{ }^{9}$. As the incidence in our study was zero, it was inferred that G6PD deficiency as a cause for neonatal jaundice in our region is rare.

\section{Conclusion}

The burden of G6PD deficiency causing neonatal jaundice is not observed in our region.

\section{References}

1. Iranpour R, Hashemipour M, Seyed-MT.New born screening for glucose-6-phosphate dehydrogenase deficiency in Isfahan. Iran J Med Screen 2008; 15:6264.

2. Fico A, Paglialunga $F$, Cigliano L, Abrescia $P$, Verde P, Martini G, et al. Glucose-6-phosphate dehydrogenase plays a crucial role in protection from redox-stress-induced apoptosis. Cell Death Differ 2004;11:823-31.

3. Beutler E. The molecular biology of G6PD variants and other red cell enzyme defects. Annul Rev Med 1992; 43:47-59.

4. Usanga EA, Ameen R. Glucose-6-phosphate dehydrogenase deficiency in Kuwait, Syria, Egypt, Iran, Jordan and Lebanon. Hum Hered 2000;50:158161.

5. Mohanty D, Mukerjee MB, Colah RB.Glucose-6phosphate deficiency in India. Indian $J$ Pediatr 2004;71:525-9.

6. Arian $\mathrm{YH}$, Bhutani VK. Prevention of Kernicterus in South Asia: role of neonatal G6PD deficiency and its identification. Indian J Pediatr2014;81(6):599-607.

7. Bhasin M K. Genetics of Castes and Tribes of India:Glucose-6-Phosphate Dehydrogenase Deficiency and Abnormal Haemoglobins ( $\mathrm{HbS}$ and HbE)M.K. J Hum Genet 2006;6(1): 49-72.

8. Pao M, Kulkarni A,GuptaV,KaulS,Balan S. Neonatal screening for glucose-6-phosphate dehydrogenase deficiency. Indian J Pediatr 2005;72(10):835-7.

9. Iranpour R. Glucose-6-phosphate dehydrogenase deficiency in neonates Indian $J$ Pediatr 2003;70(11):855-7. 